\title{
Differences in primary health care use among sub-Saharan African immigrants in Norway: a register-based study
}

\author{
Esperanza Diaz ${ }^{1,2}$, Vivian N. Mbanya ${ }^{3 *}$, Abdi A. Gele ${ }^{2,4}$ and Bernadette Kumar ${ }^{2,3}$
}

\begin{abstract}
Background: Immigrants' utilization of primary health care (PHC) services differs from that of the host populations. However, immigrants are often classified in broad groups by continent of origin, and the heterogeneity within the same continent may hide variation in use among immigrant groups at a national level. Differences in utilization of PHC between sub-Saharan African immigrants have not received much attention.

Methods: Registry-based study using merged data from the National Population Register and the Norwegian Health Economics Administration. African immigrants and their descendants registered in Norway in 2008 (36,366 persons) where included in this study. Using $x^{2}$ test and logistic regression models, we assessed the differences in the use of PHC, including general practitioner (GP) and emergency room (ER) services, and the distribution of morbidity burden for immigrants from Somalia, Ethiopia, Eritrea, and Gambia. For the analyses, we used the number of visits and medical diagnoses from each consultation registered by the physician.

Result: Among the total studied population, 66.1\% visited PHC within 1 year. The diagnoses registered were similar for all four immigrants groups, regardless of country of origin. Compared to immigrants from Somalia, the age and sex adjusted odds ratios (OR) for use of GP were significantly lower for Ethiopians (OR 0.91; 0.86-0.97), Eritreans (OR 0.85; 0.79-0.91), and Gambians (OR 0.88; 0.80-0.97). Similarly, we also observed lower use of ER among Ethiopians (OR 0.88; 0.81-0.95), Eritreans (OR 0.56; 0.51-0.62) and Gambians (OR 0.81; 0.71-0.92). However, immigrants from Somalia reduced their use of PHC with longer duration of stay in Norway. Differences between groups persisted after further adjustment for employment status.

Conclusion: Despite the similarities in diagnoses among the sub-Saharan African immigrant groups in Norway, their use of PHC services differs by country of origin and length of stay. It is important to assess the reasons for the differences in these groups to identify barriers and facilitators to access to healthcare for future interventions.
\end{abstract}

Keywords: Emigrants and immigrants, Sub-Saharan Africa, Norway, Primary health care

\section{Background}

Migration to Europe has increased substantially in the twenty-first century because of economic, political and social factors. In 2010, an estimated 72.6 million migrants lived in the European region, with migrants constituting $8.7 \%$ of the total European population [1]. Migrants represent $13.4 \%$ of the total population in Norway in 2016, with an additional $2.9 \%$ Norwegian-born to immigrant parents.

\footnotetext{
* Correspondence: vivimbanya@yahoo.com

${ }^{3}$ Department of Community Medicine and Global Health, Institute of Health and Society, Faculty of Medicine, University of Oslo, P.O Box 1130, Blindern, 0318 Oslo, Norway

Full list of author information is available at the end of the article
}

The influx of African migrants to Norway is on the rise, with African- born immigrant population representing $2.2 \%$ of the Norwegian population [2]. Somalis are the fourth largest migrant group in Norway, with a population of 41,453 immigrants, while immigrants from Eritrea $(23,618)$ and Ethiopia $(10,387)$ are among the fastest growing migrant groups in Norway. Ghana (2702), Nigeria (2348) and Gambia (1762) are also countries with an increasing immigrant population in Norway [3].

Providing equitable health care services to immigrants remains a challenge to the health care systems. In Norway, the National Health Services are decentralized, 
with municipalities providing primary health care (PHC). The Norwegian General Practitioners (GP) are the backbone of the PHC and Emergency rooms (ER) are also staffed by GPs out of hours. All immigrants with legal residence permit and asylum seekers are entitled to the same health services as Norwegian-born [4].

The extent of use of GP and ER among immigrants may vary depending on their health care needs, health care seeking behaviours, the organization of health care in their home country, practical barriers to access in the host country, health literacy, migrant's status, education level and other socioeconomic factors [5-13]. Diverse combinations of these push and pull-factors might influence the use of health care services by immigrants in Norway in different ways.

Immigrants from Africa are often considered a single group because of their geographical location, similar lifestyles, and health problems. Furthermore, in Norway, immigrants from Africa are often grouped with Asian and Latin Americans into a single immigrant population [14-17]. However, the relationship between cultural/social norms and health care utilization patterns seem to differ between nations [18-20]. Prior to migration, subSahara African (SSA) immigrants lived in countries with systems of more self-referral, higher user fees and generally low utilization of health services [21]. Nevertheless, variations in cultural and social norms, prevalence of disease, genetic admixture and health system access in their countries of origin have been described [22-25]. Also, although most immigrants from these countries are refugees, they have different educational and socioeconomic profiles [26]. Thus, once in Norway, their response to a different lifestyle and different health system might vary through different strategies to cope with communication problems, cultural differences, difficulties in their interaction with health systems and providers, and other challenges [10, 27-29].

For these reasons, the heterogeneity among immigrants from Africa should be addressed in order to detect eventual differences among groups and to be able to provide adequate responses to the differing health needs. In this study we aimed to compare the patterns of morbidity burden and the use of PHC services, including GP and ER services, among four of the largest groups of immigrants from SSA countries living in Norway.

\section{Methods}

\section{Setting and data source}

This study includes information from two national Norwegian registers: the National Population Register (NPR) and the Norwegian Health Economics Administration Database (HELFO). These registries were linked by personal identification numbers assigned to all Norwegian citizens and legal immigrants staying in Norway for 6 months or longer. This identification number entitles individuals to access to health care services similarly for immigrants and Norwegians.

Immigrants and their descendants from Somalia, Ethiopia, Eritrea and Gambia registered in Norway in 2008 ( $n=36,366$ individuals), were included in the study. Other SSA immigrant populations in Norway could not be included in the study because the groups were very small. Both first generation immigrants defined as persons born abroad to both parents from abroad and persons born in Norway, with at least one parent from the four selected SSA countries (2nd generation immigrants) were included in the study. Other combinations, like adopted children for the SSA countries, although seldom, were also included in the study to capture disparities among groups.

From the NPR, we obtained socio-demographic variables, including sex, age, marital status, urban or rural settlement, personal income in Norway (in Norwegian crowns), employment status, country of origin, and length of stay in Norway. Age was categorized into four groups for some analyses and length of stay dichotomized by 6 years since registration in Norway. Reason for migration (labour, refugee, family reunification and other reasons) was available only for those who migrated to Norway after 1990.

The HELFO-database contains administrative claims for all patient contacts within the public PHC services including consultations with GPs and ER services. From this register, we obtained information on the number of visits to GPs and ER for each individual in 2008. We used information from consultations both as dichotomous 'yes or no' and as numerical variables. Each consultation claim contains at least one medical diagnosis based on the International Classification of Primary Care (ICPC-2) registered by the physician. These ICPC-2 diagnoses were grouped according to the Major Expanded Diagnostic Clusters (MEDC) of the Johns Hopkins University Adjusted Clinical Groups (ACG ${ }^{\circ}$ Case-Mix System [30]. The ACG methodology assigns ICPC-2 codes found in claims to one of 27 MEDCs. As broad groupings of diagnosis codes, MEDCs help to remove differences in coding behaviour between practitioners. The ACG System is validated and widely used for research purposes [31].

\section{Statistical analysis}

Descriptive analyses were conducted for socioeconomic variables, use of PHC and MEDCs for the four selected countries. Subject characteristics are presented as means (standard deviation) or percentages for the variables of interest. We then analysed health service use and morbidity burden by age group, gender, and country of origin. Chi-square test and analyses of variance (ANOVA) 
were used for categorical and continuous variables, respectively, to compare the distribution and differences among immigrants from the four countries. Last, logistic regression analyses were conducted for the outcome dichotomic variables 'use of the GP' and 'use of ER' to estimate odds ratios (OR) and 95\% confidence intervals (CI) for the different countries of origin, using Somalia as a reference. Several models were conducted and results are presented for the unadjusted analyses and the two other models that better explained the use of PHC, one adjusting for age categorized in four groups and gender and the second one for gender, age categorized, and employment status. As interactions were detected between length of stay and country of origin, logistic regression analyses conducted for each of the countries separately and including the length of stay in Norway as an additional variable in the model are presented as a supplementary table. The SPSS 20.0 software package was used for statistical analyses.

\section{Results}

\section{Demographic characteristic}

Table 1 shows the number of subjects, the distribution of the study variables, and the frequency of use of PHC according to the immigrants' country of origin. The study population comprised of 36,366 SSA immigrants legally registered in 2008 in Norway. Women formed $47 \%$ of the studied population and children under 15 years of age were $38.1 \%$. Most immigrants lived in urban areas. Immigrants from Somalia were youngest, the least likely to earn an income and had the highest proportion of unmarried individuals. The mean stay for SSA immigrants was 7.6 years in Norway. With the exception of the Gambian (1.0\% refugees), for whom reason for migration was seldom registered, the majority of immigrants were registered as refugees and family reunification. Less than $1.0 \%$ in all the groups was labour migrants. Once living in Norway, the proportion of employed SSA immigrants was higher among Ethiopians, Eritreans, and Gambians compared to Somalis.

\section{Use of health care services}

A total of $66.1 \%$ of all immigrant groups visited either the GP or the ER in 2008, with annual means (standard deviations) of GP and ER visits of 2.42 (3.38), and 0.24 (0.68), respectively (Table 1 ). The proportion of each immigrant group who used PHC services by age group is presented in Table 2. The use of GP increased with age in all the four countries. Use of GP was similar for the four countries by age group, except for young adults (15-44 years) from Somalia, who used the GP more than those from the other SSA immigrants groups. For all countries, children (0-14 years) and the elderly (over 65 years) used the ER more than the other age groups
(15-64 years). Generally, Somalis were over-represented in all age groups at the ER, while Eritreans had the lowest user rates.

In binary logistic regression analyses, immigrants from Ethiopia, Eritrea and Gambia had significantly lower odds ratios of use of both GP and the ER in 2008 compared to Somalis in unadjusted and adjusted models with the exception of unadjusted analyses of GP use for Gambia (Table 3). Effect modifications between the country of origin and length of stay were however, observed when we included the length of stay in the model (Additional file 1). After adjustment for sex, age and employment status, immigrants from Somalia and Gambia significantly reduced their use of both GP and ER services after 6 years living in Norway while those from Eritrea increased their use of GP but not of ER and Ethiopians did not change their use of PHC with length of stay.

\section{Diagnoses}

Figure 1 represents the proportion of immigrants from each country with at least one MEDC registered in 2008. The most common diagnostic groups among SSA immigrants included musculoskeletal, general signs and symptoms, ear-nose-throat and respiratory related diagnoses. Generally, small differences in diagnoses among immigrants according to the country of origin were detected. Somali immigrants more often than Ethiopian, Eritrean, and Gambian had diagnoses related to ear-nose- throat ( $19.7 \%$ vs $15.7 \%, 14.8 \%$ and $15.0 \%$, respectively); general signs and symptoms $(17.8 \%$ vs $15.9 \%, 15.6 \%$ and $16.0 \%$, respectively), and respiratory (14.0\% vs $11.6 \%, 10.0 \%$ and $11.6 \%$, respectively). Immigrants from Gambia had more often musculoskeletal problems $(23.4 \%$ vs $20.5-21.2 \%$ of all the other groups, respectively).

\section{Discussion}

\section{Summary of main findings}

Our study confirms differences in the use of PHC services across the major four SSA immigrant groups in Norway. Immigrants from Somalia used the PHC services, especially ER services, more than the Ethiopian, Eritrean, and Gambian, although all had relatively similar diagnoses when in contact with the PHC.

In other European countries as well as in Norway, studies have reported differences in the use of PHC across different immigrant populations compared to natives [14, 32, 33]. Overall, our study reports lower mean number of annual visits to the GP but higher to the ER compared to what have previously been reported for immigrants from low income countries in a similar health survey comparing immigrant groups with natives in Norway [34]. As hypothesized previously, differences in the findings could be explained by 
Table 1 Characteristics of the study subjects

\begin{tabular}{|c|c|c|c|c|c|c|}
\hline Variables & Overall & Somalian & Ethiopian & Eritrean & Gambian & $P$-value \\
\hline N & 36,366 & 24,253 & 5631 & 4483 & 1999 & \\
\hline \multicolumn{7}{|l|}{ Age distribution, \% } \\
\hline $0-14$ & 38.1 & 41.2 & 34.1 & 28.5 & 33.7 & $<0.001$ \\
\hline $15-44$ & 52.2 & 50.8 & 56.0 & 56.1 & 49.9 & $<0.001$ \\
\hline $45-64$ & 8.8 & 7.0 & 9.6 & 14.5 & 16.2 & $<0.001$ \\
\hline$\geq 64$ & 0.8 & 0.9 & 0.4 & 0.9 & 0.2 & $<0.001$ \\
\hline Age, mean (SD) & $22.8(16.0)$ & $21.5(15.8)$ & $24.0(15.5)$ & $27.3(16.7)$ & $25.0(16.5)$ & \\
\hline Women, \% & 47.0 & 47.0 & 46.5 & 48.7 & 44.4 & 0.11 \\
\hline Urban settlement, \% & 83.3 & 81.9 & 86.6 & 82.6 & 92.0 & $<0.001$ \\
\hline \multicolumn{7}{|l|}{ Marital status, \%: } \\
\hline Unmarried & 64.4 & 65.0 & 63.1 & 63.7 & 61.4 & $<0.001$ \\
\hline Married & 24.5 & 23.8 & 27.7 & 27.0 & 19.2 & $<0.001$ \\
\hline Others (divorced, separated or widow) & 11.1 & 11.2 & 9.2 & 9.3 & 19.4 & $<0.001$ \\
\hline Income, mean [Norwegian crownes] & 75,827 & 53,731 & 126,980 & 118,213 & 104,721 & $<0.001$ \\
\hline \multicolumn{7}{|l|}{ Employment status, \% } \\
\hline Outside work force & 67.9 & 73.3 & 55.3 & 58.7 & 58.5 & $<0.001$ \\
\hline Employed & 26.0 & 19.9 & 40.9 & 38.0 & 35.8 & $<0.001$ \\
\hline Self-employed & 0.7 & 0.6 & 0.8 & 0.7 & 1.9 & $<0.001$ \\
\hline Unemployed & 3.3 & 4.0 & 1.9 & 1.7 & 2.4 & $<0.001$ \\
\hline Social welfare beneficiaries & 1.8 & 2.2 & 1.0 & 0.9 & 1.4 & $<0.001$ \\
\hline \multicolumn{7}{|l|}{ Immigrants, reasons of migration, \%: } \\
\hline Labour & 0.1 & 0.1 & 0.4 & 0.1 & 0.4 & $<0.001$ \\
\hline Refugee & 35.3 & 37.9 & 29.7 & 43.4 & 1.0 & $<0.001$ \\
\hline Family reunification & 25.1 & 28.8 & 19.7 & 11.5 & 25.6 & $<0.001$ \\
\hline Others & 2.2 & 0.9 & 7.5 & 1.5 & 3.4 & $<0.001$ \\
\hline Reason not specified & 37.3 & 32.3 & 42.7 & 43.5 & 69.6 & $<0.001$ \\
\hline Length of stay in Norway, mean (SD) & $7.63(7.15)$ & $6.61(5.39)$ & $8.51(9.07)$ & $9.33(9.71)$ & $13.74(8.77)$ & $<0.001$ \\
\hline \multicolumn{7}{|l|}{ Immigrants background, \% } \\
\hline Immigrant & 69.0 & 71.2 & 64.4 & 71.8 & 48.6 & $<0.001$ \\
\hline Born in Norway with immigrant parent & 23.3 & 26.3 & 14.2 & 20.4 & 18.7 & $<0.001$ \\
\hline Born out of Norway with one parent a Norwegian & 0.3 & 0.0 & 1.5 & 0.4 & 0.3 & $<0.001$ \\
\hline Born in Norway with one parent a Norwegian & 5.1 & 2.4 & 7.1 & 5.0 & 32.4 & $<0.001$ \\
\hline Born out of Norway with both parent Norwegian & 2.3 & 0.0 & 12.8 & 2.4 & 0.0 & $<0.001$ \\
\hline Norwegian nationality, \% & 56.5 & 54.2 & 58.2 & 55.4 & 81.5 & $<0.001$ \\
\hline \multicolumn{7}{|l|}{ Use of health care services, mean (SD) } \\
\hline Number of consultations with GP in 2008 & $2.42(3.38)$ & $2.48(3.41)$ & $2.29(3.30)$ & $2.33(3.45)$ & $2.14(3.01)$ & $<0.001$ \\
\hline Number of consultations at ER in 2008 & $0.24(0.67)$ & $0.27(0.72)$ & $0.22(0.61)$ & $0.14(0.48)$ & $0.19(0.53)$ & $<0.001$ \\
\hline
\end{tabular}

the pooling of heterogeneous immigrant populations in the same group in the referred study, in which immigrants were classified according to World Bank income categories. Accordingly, another study on ER use using register data from Norway from 2008 showed that immigrants from Somalia more often attended the ER compared to native Norwegians [35].
Somalis in our study used the PHC services more than other SSA immigrants; approximately 15-20\% more for GP services and 15-45\% more ER after adjustment for age, gender and employment status. Because of the nature of our study, we cannot explain the reasons for the differences in the use of $\mathrm{PHC}$. The higher frequency of PHC use among Somalis compared to the other SSA 
Table 2 Proportion of use of primary health care services across immigrants' countries of origin by age group

\begin{tabular}{|c|c|c|c|c|c|c|}
\hline & $\begin{array}{l}\text { Somalia } \\
(N=24,253)\end{array}$ & $\begin{array}{l}\text { Ethiopia } \\
(N=5631)\end{array}$ & $\begin{array}{l}\text { Eritrea } \\
(N=4483)\end{array}$ & $\begin{array}{l}\text { Gambia } \\
(N=1999)\end{array}$ & $\begin{array}{l}\text { Total } \\
(N=36,366)\end{array}$ & $P$ value \\
\hline \multicolumn{7}{|c|}{ General practitioner, \% } \\
\hline Age range: $0-14$ & 58.8 & 57.4 & 57.2 & 55.5 & 58.3 & 0.208 \\
\hline $15-44$ & 66.8 & 64.5 & 61.6 & 62.7 & 65.5 & $<0.001$ \\
\hline $45-64$ & 71.1 & 68.1 & 72.3 & 73.1 & 71.4 & 0.293 \\
\hline$\geq 65$ & 71.8 & 85.0 & 63.4 & 100 & 71.9 & 0.193 \\
\hline Total: & 63.9 & 62.5 & 61.9 & 62.0 & 63.3 & 0.016 \\
\hline \multicolumn{7}{|l|}{ Emergency room, \% } \\
\hline Age range: $0-14$ & 17.8 & 18.4 & 12.5 & 15.0 & 17.3 & $<0.001$ \\
\hline $15-44$ & 17.5 & 15.0 & 9.8 & 15.2 & 15.2 & $<0.001$ \\
\hline $45-64$ & 15.9 & 11.7 & 10.6 & 13.0 & 13.0 & 0.003 \\
\hline$\geq 65$ & 18.5 & 10.0 & 14.6 & 0.0 & 17.1 & 0.567 \\
\hline Total: & 17.5 & 15.8 & 10.7 & 14.8 & 16.3 & $<0.001$ \\
\hline
\end{tabular}

immigrant groups might be appropriate if it reflects a higher burden of disease. However, once in contact with the PHC, the distribution of the MEDCs in the four SSA groups presented more similarities than differences, suggesting other additional reasons to explain differences in use. The three most common diagnoses reported among all the immigrant populations irrespective of the country of origin were musculoskeletal, general signs and symptoms and ear, nose and throat morbidities, with the latter being most common among Somalis, probably due to the higher proportion of children. However, when compared to native Norwegians, earlier studies have pointed to an overrepresentation of non-specific diagnoses and consultations at night among Somalis at the ER [35]. In contrast to our study, studies in other countries show that immigrants from SSA have a worse health profile compared to other immigrant groups in the same country and as well as the native population $[36,37]$.

Differences among countries in our study could be explained by the characteristic of the populations, which include the diverse immigrant background of the groups. As more immigrants from Ethiopia, Eritrea, and Gambia

Table 3 Use of General Practitioner and Emergency Room services by immigrants' country of origin. Logistic regression analyses with Somalia as the reference group

\begin{tabular}{|c|c|c|c|c|c|c|}
\hline & \multicolumn{3}{|c|}{ Use of GP (yes/no) } & \multicolumn{3}{|c|}{ Use of ER (yes/no) } \\
\hline & $\overline{\mathrm{OR}}(95 \% \mathrm{Cl})$ & $P$-value & Nagelkerke $\mathrm{R}^{2}$ & OR (95\% Cl) & Nagelkerke $R^{2}$ & $P$-value \\
\hline \multicolumn{7}{|l|}{ Model 1} \\
\hline Somalia & 1 & & 0.017 & 1 & 0.007 & \\
\hline Ethiopia & $0.94(0.88-0.99)$ & 0.048 & & $0.88(0.81-0.95)$ & & 0.002 \\
\hline Eritrea & $0.92(0.86-0.98)$ & 0.012 & & $0.56(0.51-0.62)$ & & \\
\hline Gambia & $0.92(0.84-1.01)$ & 0.095 & & $0.81(0.71-0.92)$ & & 0.002 \\
\hline \multicolumn{7}{|l|}{ Model 2} \\
\hline Somalia & 1 & & 0.025 & 1 & 0.011 & \\
\hline Ethiopia & $0.91(0.86-0.97)$ & 0.004 & & $0.89(0.82-0.96)$ & & 0.005 \\
\hline Eritrea & $0.85(0.79-0.91)$ & $<0.001$ & & $0.57(0.51-0.63)$ & & $<0.001$ \\
\hline Gambia & $0.88(0.80-0.97)$ & 0.010 & & $0.83(0.73-0.94)$ & & 0.005 \\
\hline \multicolumn{7}{|l|}{ Model 3} \\
\hline Somalia & 1 & & 0.050 & 1 & 0.014 & \\
\hline Ethiopia & $0.83(0.78-0.88)$ & $<0.001$ & & $0.85(0.79-0.93)$ & & $<0.001$ \\
\hline Eritrea & $0.80(0.74-0.85)$ & $<0.001$ & & $0.55(0.50-0.61)$ & & $<0.001$ \\
\hline Gambia & $0.83(0.75-0.91)$ & $<0.001$ & & $0.80(0.70-0.91)$ & & 0.001 \\
\hline
\end{tabular}

Model 1: unadjusted; Model 2: adjusted for gender and age categorized into four groups (0-14, 15-44; 45-64 and 65+ years of age); Model 3: adjusted for gender age categorized into four groups $(0-14,15-44 ; 45-64$ and $65+$ years of age) and employment status OR Odds ratio, $95 \%$ confidence interval 


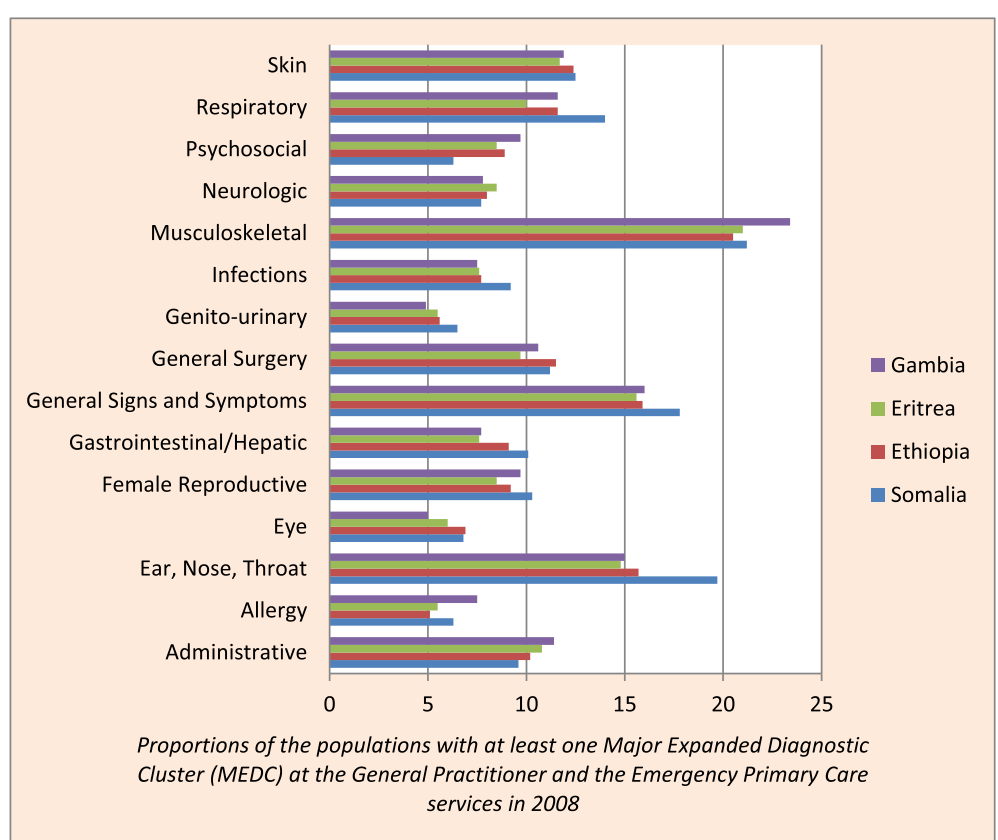

Fig. 1 Proportions of the populations with at least one Major Expanded Diagnostic Cluster (MEDC) at the General Practitioner and the Emergency Primary Care services in 2008

had at least one Norwegian parent, they probably encountered less communication challenges and had higher knowledge regarding health care services. Socioeconomic status, with Somalis having the lowest income in Norway, could also partially play a role, although our adjusted model including employment status still showed dissimilarities among groups. Variation in the use of PHC in our study might also be explained by differences in unmet health care needs, formal and informal information about how to access PHC or satisfaction with the health system organization in terms of patients/providers interaction, waiting time to get an appointment or convenience of hours of service. Other individual factors like health literacy, fear of stigma or differences in acculturation and combination of stress related to pre-migration and migration experiences can be differentially distributed between groups $[10,20,38,39]$.

The length of stay is often used as a proxy for acculturation to the new country, and in our study was differentially related to $\mathrm{PHC}$ use for the four countries of origin. Duration of stay in immigrants' host countries tends to improve immigrants' knowledge of the health care system, language skills and consequently improves utilization of health care services [40]. On the other hand, although immigrants tend to be healthier when they arrive at a new country, which is known as the healthy immigrant effect, their health worsens with time in the new country quicker than the host population $[41,42]$. Previous studies show therefore a general increase in the use of health services after some years in the new country
$[16,43]$. In our study, however, the pattern seems to be reversed for immigrants from Somalia and Gambia. These results should further be studied qualitatively to better understand the underlying causes.

\section{Strengths and limitations of the study}

Using register data with nationwide coverage is the main strength of our study, as it gives us enough numbers to be able to disaggregate SSA into country of origin. The use of administrative data minimalizes self-reported bias. In addition, several socioeconomic and migration-related characteristics were available giving us the possibility of adjusting for the variables that better explained the use of PHC, although many factors related to health and health care use remains unmeasured and some variables, like reason for migration, were not specified in a sufficient number of participants to be included in the models. Our study had, however, also limitations. Firstly, our data lack information about patients using private clinics in PHC. Although the Norwegian health care system is mostly public and base on a gate-keeper function of the GP, patients already referred to the specialist or attending only private clinics will appear as if they have not been in contact with PHC. Secondly, our HELFOdatabase does not include patient's information for elderly residing in the nursing homes, which may explain part of the elderly populations' low utilization of the PHC services. Last, the diagnoses in our study were based on ICPC-codes registered for administrative claims and not extracted from electronic records. 
Generally, these claims include only one diagnose disregarding the number of diseases the patient might present and therefore cannot be used for estimating actual prevalences of diseases. However, the ICPC- codes have far been used and recommended to be an adequate and reliable classification system for comparison of groups in primary health care [44].

\section{Conclusion}

Although Somalis, Ethiopia, Eritrea and the Gambians have a similar distribution of diagnosis, differences exist in their use of GP and ER, with immigrants from Somalia using the PHC system more often than the other groups. However, immigrants from Somalia seem to reduce their use of PHC with a longer duration of stay in Norway. Differences among immigrants from the four sub-Saharan countries should be further explored in order to inform policy makers to attain equity in the provision of $\mathrm{PHC}$.

\section{Additional file}

Additional file 1: Logistic regression of migrants' use of primary health care services by sex, age groups, employment and, length of stay. The supplemental table shows the results of the logistic regressions of immigrant's from different sub-Saharan African countries (Somalia, Ethiopia, Eritrea and Gambia) and the use of the general practitioner and the emergency room by sex, different age groups, those employed and the immigrants' length of stay in Norway. (DOCX $15 \mathrm{~kb}$ )

\section{Abbreviations}

ACG: Adjusted clinical groups; ENT: Ear nose throat; ER: Emergency room; GP: General practitioner; HELFO: Norwegian health economics administrative database; ICPC: International classification of primary care; MEDC: Major expanded diagnostic clusters; NPR: National population registry; OR: Odds ratio; PHC: Primary health care; SD: Standard deviation; SSA: Sub-Saharan Africa; WHO: World Health Organization

\section{Acknowledgements}

We thank the University of Oslo for the financial support.

\section{Funding}

University of Oslo (UiO), Norway.

\section{Availability of data and materials}

The datasets generated and/or analysed during the current study are not publicly available because it is a Norwegian National Registry data, under the management of the Department of Global Public Health and Primary Care, University of Bergen, but are available from the first author on reasonable request.

\section{Authors' contributions}

ED: designed the study and conducted the analyses, VM: Wrote and revised the paper. ED, VM, AG, BK: edited and approved the final manuscript.

\section{Ethics approval and consent to participate}

This study is part of the main study "Immigrant health in Norway", and was approved by the Norwegian Regional Committee for Medical and Health Research Ethics (2016/799/REK Vest), which waived the need for a written patient consent because, the study was based on national Norwegian registers.

\section{Consent for publication}

Not applicable.

\section{Competing interests}

The authors declare that they have no competing interest.

\section{Publisher's Note}

Springer Nature remains neutral with regard to jurisdictional claims in published maps and institutional affiliations.

\section{Author details}

1Department of Global Public Health and Primary Care, University of Bergen, Bergen, Norway. ${ }^{2}$ Norwegian Centre for Minority Health Research, Oslo, Norway. ${ }^{3}$ Department of Community Medicine and Global Health, Institute of Health and Society, Faculty of Medicine, University of Oslo, P.O Box 1130, Blindern, 0318 Oslo, Norway. ${ }^{4}$ Department of Nursing and Health Promotion, Faculty of Health Sciences, Oslo and Akershus University College of Applied Sciences, Oslo, Norway.

Received: 25 November 2016 Accepted: 21 June 2017

Published online: 28 July 2017

\section{References}

1. Rechel B, Mladovsky P, Ingleby D, Mackenbach JP, McKee M. Migration and health in an increasingly diverse Europe. Lancet. 2013;381(9873):1235-45.

2. Immigrants and Norwegian-born to immigrant parents, 1 January 2016 [Internet]. [cited 19 Sept 2016]. Available from: http://www.ssb.no/en/ befolkning/statistikker/innvbef/aar/2016-03-03?fane=tabell\&sort= nummer\&tabell=258404

3. Immigrants and Norwegian-born to immigrant parents, foreign-born and foreign citizens, by country background, by contry of birth and citizenship. 1 January (SY 92) [Internet]. January 2017. Available from: http://www.ssb. no/304491/immigrants-and-norwegian-born-to-immigrant-parents. 1-januarysy-92. Accessed 19 Sept 2016.

4. Ånen Ringard AS, Ingrid Sperre Sauness, Anne Karin Lindahl. Health system in transition: Norwegian health system review by Norwegian knowledge Center for Health Services: 2013.

5. Alas AN, Dunivan GC, Wieslander CK, Sevilla C, Barrera B, Rashid R, et al. Health care disparities among English-speaking and Spanish-speaking Women with pelvic organ Prolapse at public and private hospitals: what are the barriers? Female pelvic medicine \& reconstructive surgery. 2016.

6. Woudstra AJ, Dekker E, Essink-Bot ML, Suurmond J. Knowledge, attitudes and beliefs regarding colorectal cancer screening among ethnic minority groups in the Netherlands - a qualitative study. Health Expect. 2016;19(6): 1312-23. doi:10.1111/hex.12428.

7. Tessema GA, Laurence CO, Mahmood MA, Gomersall JS. Factors determining quality of care in family planning services in Africa: a systematic review protocol. JBI Database Syst Rev Imple Rep. 2016;14(8): 103-14.

8. Chawla SS, Gupta S, Onchiri FM, Habermann EB, Kushner AL, Stewart BT. Water availability at hospitals in low- and middle-income countries: implications for improving access to safe surgical care. J Surg Res. 2016; 205(1):169-78

9. Ali JS, McDermott S, Gravel RG. Recent research on immigrant health from statistics Canada's population surveys. Can J Public Health. 2004;95(3):19-13.

10. Gele AA, Torheim LE, Pettersen KS, Kumar B. Beyond culture and language: access to diabetes preventive health services among Somali Women in Norway. J Diabetes Res. 2015;2015:549795.

11. Karaceper MD, Chakraborty P, Coyle D, Wilson K, Kronick JB, Hawken S, et al. The health system impact of false positive newborn screening results for medium-chain acyl-CoA dehydrogenase deficiency: a cohort study. Orphanet J Rare Dis. 2016;11(1):12.

12. Newbold B. Health status and health care of immigrants in Canada: a longitudinal analysis. J Health Serv Res Policy. 2005;10(2):77-83.

13. Sproston KA, Pitson LB, Walker E. The use of primary care services by the Chinese population living in England: examining inequalities. Ethn Health. 2001;6(3-4):189-96.

14. Diaz E, Calderon-Larranaga A, Prado-Torres A, Poblador-Plou B, Gimeno-Feliu LA. How do immigrants use primary health care services? A register-based study in Norway. Eur J Pub Health. 2015;25(1):72-8.

15. Diaz E, Kumar BN. Differential utilization of primary health care services among older immigrants and Norwegians: a register-based comparative study in Norway. BMC Health Serv Res. 2014;14:623. 
16. Diaz E, Kumar BN, Gimeno-Feliu LA, Calderon-Larranaga A, Poblador-Pou B, Prados-Torres A. Multimorbidity among registered immigrants in Norway: the role of reason for migration and length of stay. Trop Med Int Health. 2015;20(12):1805-14

17. Elstad JI, Finnvold JE, Texmon I. Sykehusinnleggelser og bruk av spesialisthelsetjenester blant pasienter med norsk og utenlandsk bakgrunn - en deskriptiv studie. 2015.

18. Van der Stuyft P, De Muynck A, Schillemans L, Timmerman C. Migration, acculturation and utilization of primary health care. Soc Sci Med. 1989;29(1): 53-60.

19. Smaje C, Grand JL. Ethnicity, equity and the use of health services in the British NHS. Soc Sci Med. 1997;45(3):485-96.

20. Patel S. Intercultural consultations. Language is not the only barrier. BMJ. 1995;310(6973):194.

21. Mujasi PN, Asbu EZ, Puig-Junoy J. How efficient are referral hospitals in Uganda? A data envelopment analysis and tobit regression approach. BMC Health Serv Res. 2016;16(1):230.

22. Masiye F. Investigating health system performance: an application of data envelopment analysis to Zambian hospitals. BMC Health Serv Res. 2007;7:58

23. Sebastian MS, Lemma H. Efficiency of the health extension programme in Tigray, Ethiopia: a data envelopment analysis. BMC Int Health Hum Rights. 2010;10:16.

24. Agyemang C, Bhopal R, Bruijnzeels M. Negro, black, black African, African Caribbean, African American or what? Labelling African origin populations in the health arena in the 21 st century. J Epidemiol Community Health. 2005;59(12):1014-8.

25. Commodore-Mensah Y, Himmelfarb CD, Agyemang C, Sumner AE. Cardiometabolic health in African immigrants to the United States: a call to reexamine research on African-descent populations. Ethn Dis. 2015;25(3):373-80.

26. Refugees in Norway [Internet]. [cited 19 Sept 2016]. Available from: http:// www.ssb.no/en/befolkning/artikler-og-publikasjoner/refugees-in-norway.

27. Hakonsen H, Lees K, Toverud EL. Cultural barriers encountered by Norwegian community pharmacists in providing service to non-western immigrant patients. Int J Clin Pharm. 2014;36(6):1144-51.

28. Kale E, Skjeldestad K, Finset A. Emotional communication in medical consultations with native and non-native patients applying two different methodological approaches. Patient Educ Couns. 2013;92(3):366-74.

29. Olsson EM. Interpersonal complaints regarding cancer care through a gender lens. Int J Health Care Qual Assur. 2016;29(6):687-702.

30. Jonathan PW, Chad A. The Johns Hopkins ACG ${ }^{\circledR}$ System TRG, Version 10.0, December 2011. Health Services Research \& Development Center at The Johns Hopkins University, Bloomberg School of Public Health. December 2011.

31. Calderon-Larranaga A, Gimeno-Feliu LA, Macipe-Costa R, Poblador-Plou B, Bordonaba-Bosque D, Prados-Torres A. Primary care utilisation patterns among an urban immigrant population in the Spanish National Health System. BMC Public Health. 2011;11:432.

32. Uiters E, Deville W, Foets M, Spreeuwenberg P, Groenewegen PP. Differences between immigrant and non-immigrant groups in the use of primary medical care; a systematic review. BMC Health Serv Res. 2009;9:76.

33. Nørredam M, Nielsen SS, Krasnik A. Migrants' utilization of somatic healthcare services in Europe-a systematic review. Eur J Pub Health. 2010; 20(5):555-63.

34. Diaz E, Calderón-Larrañaga A, Prado-Torres A, Poblador-Plou B, Gimeno-Feliu L-A. How do immigrants use primary healthcare services? A register-based study in Norway. Eur J Public Health. 2015;25(1):72-8.

35. Sandvik H, Hunskaar S, Diaz E. Immigrants' use of emergency primary health care in Norway: a registry-based observational study. BMC Health Serv Res. 2012;12:308

36. Johnson EB, Reed SD, Hitti J, Batra M. Increased risk of adverse pregnancy outcome among Somali immigrants in Washington state. Am J Obstet Gynecol. 2005:193(2):475-82.

37. Garg PK, Perry S, Dorn M, Hardcastle L, Parsonnet J. Risk of intestinal helminth and protozoan infection in a refugee population. Am J Trop Med Hyg. 2005;73(2):386-91.

38. Falgas I, Ramos Z, Herrera L, Qureshi A, Chavez L, Bonal C, et al. Barriers to and correlates of retention in Behavioral health treatment among Latinos in 2 different host countries: the United States and Spain. JPHMP: Journal of public health management and practice; 2016.

39. Deville W, Greacen T, Bogic M, Dauvrin M, Dias S, Gaddini A, et al. Health care for immigrants in Europe: is there still consensus among country experts about principles of good practice? A Delphi study. BMC Public Health. 2011:11:699.

40. Vazquez ML, Vargas I, Jaramillo DL, Porthe V, Lopez-Fernandez LA, Vargas H, et al. Was access to health care easy for immigrants in Spain? The perspectives of health personnel in Catalonia and Andalusia. Health Policy. 2016;120(4):396-405.

41. Kennedy S, Kidd MP, McDonald JT, Biddle N. The healthy immigrant effect: patterns and evidence from four countries. Int Migr Integ. 2015;16:317-32.

42. Razum O, Zeeb H, Rohrmann S. The 'healthy migrant effect'- not merely a fallacy of inaccurate denominator figures. Int J Epidemiol. 2000;29(1):191-2.

43. Gimeno-Feliu LA, Calderon-Larranaga A, Diaz E, Poblador-Plou B, MacipeCosta R, Prados-Torres A. Global healthcare use by immigrants in Spain according to morbidity burden, area of origin, and length of stay. BMC Public Health. 2016;16:450.

44. Frese T, Herrmann K, Bungert-Kahl P, Sandholzer H. Inter-rater reliability of the ICPC-2 in a German general practice setting. Swiss Med Wkly. 2012;142: w13621.

\section{Submit your next manuscript to BioMed Central and we will help you at every step:}

- We accept pre-submission inquiries

- Our selector tool helps you to find the most relevant journal

- We provide round the clock customer support

- Convenient online submission

- Thorough peer review

- Inclusion in PubMed and all major indexing services

- Maximum visibility for your research

Submit your manuscript at www.biomedcentral.com/submit

) Biomed Central 